\title{
Impact of Biodiesel Source Material on the Oxidation Stability of the Final Blends
}

\author{
Muhammad Ismail Joyan* \\ Lecturer in Department of General Chemistry, Technology Chemical Engineering Faculty of Jawzjan \\ University, Sheberghan, Afghanistan
}

*Corresponding Author: Muhammad Ismail Joyan, Lecturer in Department of General Chemistry, Technology Chemical Engineering Faculty of Jawzjan University, Sheberghan, Afghanistan.

\begin{abstract}
Biodiesel is non-toxic, free of sulphur and aromatics, readily biodegradable, safe to handle, enhances lubricity and its main physicochemical properties are comparable to those of conventional middle distillate fuels. But the nature of biodiesel makes it more sensitive to oxidation than petroleum diesel during long-term storage. The greater the level of unsaturation in an alkyl ester, the more susceptible it will be to oxidation. Oxidation stability is thus a parameter that describes the degradation tendency of biodiesel and is of great importance in the context of possible problems with engine parts. The purpose of this study was to investigate the impact of biodiesel source material on the oxidation stability of the final blends. The results indicated that the trend of the induction period has a direct correlation with the percentage of saturated fatty acids in the biodiesel.
\end{abstract}

Keywords: Biodiesel, oxidation stability, methyl esters, linoleic acid.

\section{INTRODUCTION}

Biodiesel is an alternative diesel fuel consisting of long-chain fatty acid methyl esters (FAME) derived from vegetable oils, used frying oils and animal fats. Biodiesel is chemically produced through the transesterification reaction of a triglyceride with an alcohol (methanol or ethanol) in the presence of an alkaline or acidic catalyst (Rashid and Anwar, 2008). Several articles report on the beneficial characteristics of biodiesel. It is non-toxic, free of sulphur and aromatics, readily biodegradable, safe to handle, enhances lubricity and its main physicochemical properties are comparable to those of conventional middle distillate fuels (Schinas et al., 2009; Bautista et al., 2009; Raheman and Ghadge, 2007). Despite its many advantages, biodiesel's nature makes it more sensitive to oxidation than petroleum diesel during long-term storage. The sensitivity varies, depending on the raw material, the presence of naturally occurring antioxidants and the storage conditions (Dunn et al., 2008; Tang et al., 2008).

The mechanism for biodiesel oxidation is well known (Lapuerta et al., 2012). The oxidation stability depends on the composition of the oil source, the unsaturated and polyunsaturated methyl esters being the more reactive species. The greater the level of unsaturation in an alkyl ester, the more susceptible it will be to oxidation. In any case, besides depending on the degree and configurations of olefinic unsaturations, the resistance of biodiesel against oxidation will also be dependent on the presence of antioxidants and on storage conditions.

The oxidation kinetics of biodiesel has been studied as well as the effect of antioxidants (Xin et al., 2009). Since oxidation products can cause many problems in diesel engines (Knothe, 2007; Lapuerta et al., 2008), it is important to prevent oxidation by adding additives such as butylated hydroxyanisole (BHA), pyrogallol (PA), butylated hydroxytoluene (BHT), and other commercial products such as Baynox (Lanxess), Bioextend (Eastman), and Ethanox 4760E (Albemarle). Several papers dealing with natural (Liang et al., 2006; Santos et al., 2012) and synthetic (Dunn, 2005; Liang et al., 2006; Karavalakis et al., 2011; Focke et al., 2012) antioxidants for biodiesel can be found in the literature, reflecting that the search for new alternative low-cost additives is currently a major issue.

In this context, the use of different experimental techniques to evaluate the oxidation stability of biodiesel has been discussed (Hoshino et al., 2007), as methods based on FTIR (Araújo et al., 2011), 
thermogravimetry (Kivevele et al., 2011; Santos et al., 2012), or DSC (García-Pérez et al., 2010). The standardized accelerated oxidation test accepted in EN14112 and ASTM D6751 standards is the usually called Rancimat method (Maia et al., 2011; Focke et al., 2012; Lapuerta et al., 2012). A new determination method was reported by Neumann et al. (2008), which provides a more rapid test to measure oxidation stability than the Rancimat method, called Petrooxy method.

Oxidation stability is thus a parameter that describes the degradation tendency of biodiesel and is of great importance in the context of possible problems with engine parts. The main oxidation products are peroxides and hydroperoxides. During further degradation, these products form shorter-chain compounds such as low molecular weight acids, aldehydes, ketones and alcohols. Reactions with the unstable hydroperoxide species with another fatty acid chain may form high molecular weight materials, such dimer or trimer acids which may lead to filter blocking, injector failures and deposit formation. The purpose of this study was to investigate the impact of biodiesel source material on the oxidation stability of the final blends.

\section{Materials AND Method}

\subsection{Feedstocks}

The feedstocks used for the production of BD-1 were $65 \%$ refined rapeseed oil and $35 \%$ used frying oils. BD-2 derived from $36 \%$ used frying oils, $20 \%$ palm oil and $44 \%$ soybean oil, while BD-3 feedstocks were $32 \%$ used frying oils, $32 \%$ soybean oil and $36 \%$ rapeseed oil. BD-4 was produced from pure rapeseed oil. Table 1 shows the main fatty acids of all biodiesel samples used in this study.

\subsection{Oxidation Stability Measurements}

The oxidation stability was quantified by the induction period (IP) of neat methyl esters and their blends with automotive diesel. The IP was evaluated according to the Rancimat method EN 14112 for pure biodiesel and the modified Rancimat method EN 15751 for the biodiesel blends. In the modified Rancimat method, a number of parameters were changed, mainly due to the higher volatility of hydrocarbon fuels compared to methyl esters, which may lead to higher sample evaporation. The changes include elongated reaction vessels and higher amount of distilled water, while the evaluation of the IP can be only performed manually ( 2 tangents). All stability measurements were carried out on a Metrohm 873 Biodiesel Rancimat Instrument. Samples of $3 \mathrm{~g}$ of pure biodiesel and $7.5 \mathrm{~g}$ of biodiesel blends respectively, were analyzed under constant air flow of $10 \mathrm{~L} / \mathrm{h}$ passing through the fuel and into a vessel containing distilled water (HPLC water). The samples were held at $110^{\circ} \mathrm{C}$ heating block temperature, with a temperature correction factor DT to be set to $1.5^{\circ} \mathrm{C}$ (as recommended by the test method). As soon as volatile organic acids (mainly acetic and formic) are formed in the sample, this is indicated by an increase in conductivity in the measuring vessel. The time that elapses until the secondary oxidation products are detected, is known as the induction period.

\section{RESULTS AND DISCUSSION}

Physicochemical properties of methyl esters of biodiesel were determined and represented in table-1. Fatty acid composition of the methyl estersis presented in table- 2 .

Table1. Physicochemical Properties of the Methyl Esters

\begin{tabular}{|c|c|c|c|c|}
\hline Properties & BD1 & BD2 & BD3 & BD4 \\
\hline Viscosity $\left(\mathrm{mm}^{2} / \mathrm{s}, 40^{\circ} \mathrm{C}\right)$ & 4.2 & 4.1 & 4.4 & 4.09 \\
\hline Density $\left(\mathrm{g} / \mathrm{cm}^{3}, 15^{\circ} \mathrm{C}\right)$ & 0.881 & 0.882 & 0.888 & 0.883 \\
\hline Water content $\left(\mu \mathrm{g} \mathrm{g}^{-1}\right)$ & 348 & 367 & 355 & 765 \\
\hline Cold filter plugging point, CFPP $\left({ }^{\circ} \mathrm{C}\right)$ & -1 & -2 & -5 & -2 \\
\hline Iodine number & 119 & 102 & 119 & 115 \\
\hline Acid value (mg KOH /g) & 0.11 & 0.15 & 0.12 & 0.48 \\
\hline Oxidation stability $\left(110^{\circ} \mathrm{C}, \mathrm{h}\right)$ & 4.32 & 5.21 & 4.89 & 5.06 \\
\hline Monoglyceride content $(\% \mathrm{~m} / \mathrm{m})$ & 0.21 & 0.35 & 0.39 & 0.45 \\
\hline Diglyceride content $(\% \mathrm{~m} / \mathrm{m})$ & 0.081 & 0.076 & 0.099 & 0.06 \\
\hline Triglyceride content $(\% \mathrm{~m} / \mathrm{m})$ & 0.09 & 0.078 & 0.081 & 0.184 \\
\hline Total glycerol $(\% \mathrm{~m} / \mathrm{m})$ & 0.085 & 0.075 & 0.101 & 0.154 \\
\hline
\end{tabular}

Table2. Fatty Acid Composition of the Methyl Esters

\begin{tabular}{|c|c|c|c|c|}
\hline Fatty acid & BD1 & BD2 & BD3 & BD4 \\
\hline C12:0 & - & - & - & 0.21 \\
\hline C14:0 & 0.19 & 0.21 & 0.11 & 0.01 \\
\hline
\end{tabular}




\begin{tabular}{|c|c|c|c|c|}
\hline \multicolumn{5}{|l}{} \\
\hline $\mathrm{C} 16: 0$ & 11.98 & 12.31 & 7.97 & 6.8 \\
\hline $\mathrm{C} 18: 0$ & 3.16 & 3.18 & 2.35 & 2.75 \\
\hline $\mathrm{C} 18: 1$ & 21.43 & 22.56 & 31.09 & 26.22 \\
\hline
\end{tabular}

Oxidation stability of biodiesel samples Fig. 1 shows the changes recorded on the oxidation stability of the nine biodiesel samples. Two measurements are presented for each sample, spaced approximately 3 weeks apart. It should be mentioned, that certain biodiesel properties such as those of acid value, water content and ester content were not found to significantly differ during the test period. The samples of BD-1, BD-2, BD-3 and BD-4 were found well below the minimum induction period of $6 \mathrm{~h}$. These samples mainly comprised unsaturated methyl esters and were free of antioxidant.

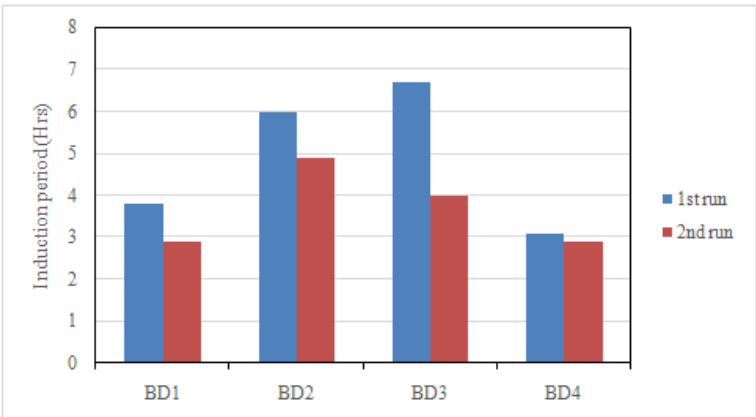

Figure1. Changes on the Oxidation Stability of the Methyl Esters during Storage

The biodiesel stability generally depends upon the fatty acid profile of the parent feedstock. Therefore, biodiesels with high unsaturated fatty acid contents, such as linoleic and linolenic acids, are especially prone to oxidation. Oxidation of biodiesel starts with the abstraction (removal) of hydrogen atoms from the "allylic" position next to the double bond to produce a carbon free radical. If diatomic oxygen is present, therefore, the subsequent reaction to form a peroxyradical is extremely fast. The peroxy free radical is not as reactive as the carbon free radical but is sufficiently reactive to quickly abstract hydrogen from a carbon to form another carbon radical and a hydroperoxide $(\mathrm{ROOH})$. The new carbon free radical can then react with diatomic oxygen to continue the propagation cycle. This chain reaction terminates when two free radicals react with each other to yield stable products, such as aldehydes, shorter chain carboxylic acids, insolubles, gum, and sediments. When biodiesel containing this oxidationproducts is used in the engine, it impairs the engine performance because of fuel filter plugging, injector fouling, and deposit formation in the engine combustion chamber and various components of the fuel system (Jain and Sharma, 2010).

Several studies related to the stability of biodiesel have been reported in the literature. A number of researchers have investigated the oxidation stability of biodiesel synthesized from most common oils (Dunn, 2002; 2005; Ferrari et al., 2005; Liang et al., 2006; Bondioli et al., 2003). However, increasing the production of biodiesel from conventional sources (soybean, rapeseed, palm, etc.) has placed strain on food production, its price and availability. Therefore, the search for additional regional biodiesel feedstocks is an important objective (Sarin et al., 2007; Rashid et al., 2008). There are few studies reported on oxidation stability of biodiesel from less common or unconventional oils. Sarin et al.11 reported oxidation stability of biodiesel derived from tree-borne non-edible oil seeds, such as Jatropha and karanja, and compared it to biodiesel derived from edible oils, such as palm and sunflower oils. It was found that the trend of the induction period has a direct correlation with thepercentage of saturated fatty acids in the biodiesel.

\section{REFERENCES}

[1] Araújo SV, Rocha, B. S., Luna, F. M. T., Rola, E. M. Jr., Azevedo, D. C. S., and Cavalcante, C. L. Jr. (2011). FTIR assessment of the oxidation process of castor oil FAME submitted to PetroOXY and Rancimat methods. Fuel Process. Technol. 92, 1152-1155.

[2] Bautista LF, Vicente G, Rodriguez R, Pacheco M. (2009). Optimization of FAME production from waste cooking oil for biodiesel use. Biomass Bioenergy 2009; 33:862-72.

[3] Bondioli P,Gasparoli A, Bella LD, Taghliabue S, Toso, G. (2003). Biodiesel stability under commercial storage conditions over one year. Eur. J. Lipid Sci. Technol. 105, 735-74. 
[4] Dunn RO. (2008). Antioxidants for improving storage stability of biodiesel. Biofuels, Bioproducts Biorefining. 2:304-18.

[5] Dunn R. (2002). Effect of oxidation under accelerated conditions on fuel properties of methyl soyate (biodiesel). J. Am. Oil Chem. Soc. 79(9): 915-920.

[6] Dunn RO. (2005). Effect of antioxidants on the oxidative stability of methyl soyate (biodiesel). Fuel Process. Technol. 86, 1071-1085.

[7] Ferrari R, Oliveira V, Scabio A. (2005). Oxidative stability of biodiesel from soybean oil fatty acid ethyl esters. Sci. Agric. 62, 291-295.

[8] Focke WW, Westhuizen IVD, Grobler ABL, Nshoane KT, Reddy JK, and Luyt AS. (2012). The effect of synthetic antioxidants on the oxidative stability of biodiesel. Fuel 94, 227-233.

[9] García-Pérez M, Chaala A, Pakdel H, Kretschmer D, Roy C. (2007). Characterization of bio-oils in chemical families. Biomass Bioenergy 31, 222-242.

[10] Hoshino T, Iwata Y, Koseki H. (2007). Oxidation stability and risk evaluation of biodiesel. Therm. Sci. 11, $87-100$.

[11] Jain S, Sharma MP. (2010). Stability of biodiesel and its blends: A review. Renewable Sustainable Energy Rev. 14(2): 667-67.

[12] Karavalakis G, Hilari D, Givalou L, Karonis D, Stournas S. (2011). Storage stability and ageing effect of biodiesel blends treated with different antioxidants. Energy 36, 369-374.

[13] KiveveleTT Mbarawa MM, Bereczky A, Laza T, Madarasz J. (2011). Impact of antioxidant additives on the oxidation stability of biodiesel produced from Croton Megalocarpus oil. Fuel Process. Technol. 92, 1244-1248.

[14] Knothe G. (2007). Some aspects of biodiesel oxidative stability. Fuel Process. Technol. 88, 669-677.

[15] Lapuerta M, Rodríguez-Fernández J, RamosÁ, and Álvarez B. (2012). Effect of the test temperature and anti-oxidant addition on the oxidation stability of commercial biodiesel fuels. Fuel 93, 391-396.

[16] Liang YC, May CY, Foon CS, Ngan MA, Hock CC, and Basiron Y. (2006). The effect of natural and synthetic antioxidants on the oxidative stability of palm diesel. Fuel 85, 867-870.

[17] Maia ECR, Borsato D, Moreira I, Spacino KR, Rodrigues PRP, and Gallina AL. (2011). Study of the biodiesel B100 oxidative stability in mixture with antioxidants. Fuel Process. Technol. 92, 1750-1755.

[18] Neumann A, Jebens T, and Wiembicki V. (2008). A method for determining oxidation stability of petrodiesel, biodiesel, and blended fuels. Am. Lab. 40, 22-26.

[19] Raheman H, Ghadge SV (2007). Performance of compression ignition engine with mahua (Madhucaindica) biodiesel. Fuel. 86:2568-73.

[20] Rashid U, Anwar F. (2008) Production of biodiesel through optimized alkaline catalyzed transesterification of rapessed oil. Fuel 2008; 87:265-73.

[21] RashidU, Anwar F, Moser BR,Knothe G. (2008) Moringa oleifera oil: A possible source of biodiesel. Bioresour. Technol. 99(17), 8175-8179.

[22] Santos NA, Cordeiro AMTM, Damasceno SS, Aguiar RT, Rosenhaim R, Carvalho Filho JR, et al. (2012). Commercial antioxidants and thermal stability evaluations. Fuel 97, 638-643.

[23] Sarin R, Sharma M,Sinharay S, Malhotra RK. (2007). Jatrophapalm biodiesel blends: An optimum mix for Asia. Fuel. 86 (1011), 1365-1371.

[24] Schinas P, Karavalakis G, Davaris C, Anastopoulos G, Karonis D, Zannikos F, et al. (2009). Pumpkin (Cucurbita pepo L.) seed oil as an alternative feedstock for the production of biodiesel in Greece. Biomass Bioenergy. 33:44-9.

[25] Tang H, De Guzman RC, Salley SO, Ng SKY. (2008). The oxidative stability of biodiesel: effects of FAME composition and antioxidant. Lipid Technol. 20:249-52.

[26] Xin J, Imahara H, and Saka S. (2009). Kinetics on the oxidation of biodiesel stabilized with antioxidant. Fuel 88, 282-286.

Citation: Muhammad Ismail Joyan, (2020). “Impact of Biodiesel Source Material on the Oxidation Stability of the Final Blends", International Journal of Petroleum and Petrochemical Engineering (IJPPE), 6(1), pp.2427, DOI: http://dx.doi.org/10.20431/2454-7980.0601003

Copyright:@ 2020Authors. This is an open-access article distributed under the terms of the Creative Commons Attribution License, which permits unrestricted use, distribution, and reproduction in any medium, provided the original author and source are credited. 